\title{
Optimizing blood pressure control through the use of fixed combinations
}

\author{
This article was published in the following Dove Press journal: \\ Vascular Health and Risk Management \\ 7 May 2010 \\ Number of times this article has been viewed
}

\author{
Rainer Düsing \\ Medizinische Klinik und \\ Poliklinik I, Bonn, Germany
}

Correspondence: Rainer Düsing Medizinische Klinik und Poliklinik I, Wilhelmstr. 35-37, 53 I I I Bonn, Germany Tel +49 22828722343

Fax +4922828722593

Email duesing@uni-bonn.de
Abstract: The majority of hypertensive patients need $\geq 2$ antihypertensive agents to reach goal blood pressure. As an estimate, one-third of unselected hypertensive patients may be successfully treated with monotherapy, one-third may require 2 and the remaining one-third of patients will need $\geq 3$ antihypertensive agents for effective blood pressure control. However, doctors are often hesitant to expand therapy in treated patients whose blood pressure is not lowered to goal (therapeutic inertia). Multiple-drug therapy in the majority of hypertensive patients may also represent one of several factors responsible for the low rates of adherence with chronic antihypertensive treatment. As a consequence, both US and European guidelines recommend single pill combinations to lower the number of pills needed in order to increase medication adherence and, possibly, reduce therapeutic inertia. For 2 drug combinations, the recently revised European (ESC/ESH) guidelines recommend the following options: diuretic plus either calcium channel blocker (CCB) or renin-angiotensin system (RAS) blocker (angiotensin-converting enzyme inhibitor or angiotensin receptor blocker) or CCB plus RAS-blocker. In the absence of substantial evidence, neither JNC-7 (from 2003) nor the European guidelines from 2007 give any meaningful advice on triple combination treatment. It is therefore of interest that the 2009 reappraisal of the European guidelines gives preference to the combination of a RAS blocker and a CCB plus a diuretic. On the background of the substantial number of patients requiring $\geq 3$ drugs for blood pressure control, the recent approval of a single-pill 3-drug combination composed in accordance with the above mentioned ESC/ESH recommendations should be appreciated.

Keywords: blood pressure, fixed-dose combinations, hypertension

\section{Introduction}

Hypertension represents a cardiovascular risk factor with a substantial impact on morbidity and mortality. In the Global Burdon of Disease study, worldwide mortality in the year 2001 was analyzed with respect to underlying risk factors. In that study, between 7 and 8 million of the approximately 56 million fatalities could be attributed to arterial hypertension, supporting the notion that hypertension remains the most aggressive risk factor to date. ${ }^{1}$ The identification of hypertension as an important risk factor has been paralleled by continuous efforts to develop more effective and tolerable antihypertensive agents. Thus, over the past 6 decades we have seen an impressive evolution of antihypertensive agents (Figure 1). However, in spite of a broad range of available antihypertensive drugs, the percentage of hypertensive patients who are treated and have a blood pressure in the control range (usually $<140 / 90 \mathrm{mmHg}$ ) remains low. ${ }^{2-4}$ It has recently been proposed that the high and even increasing number of patients with 


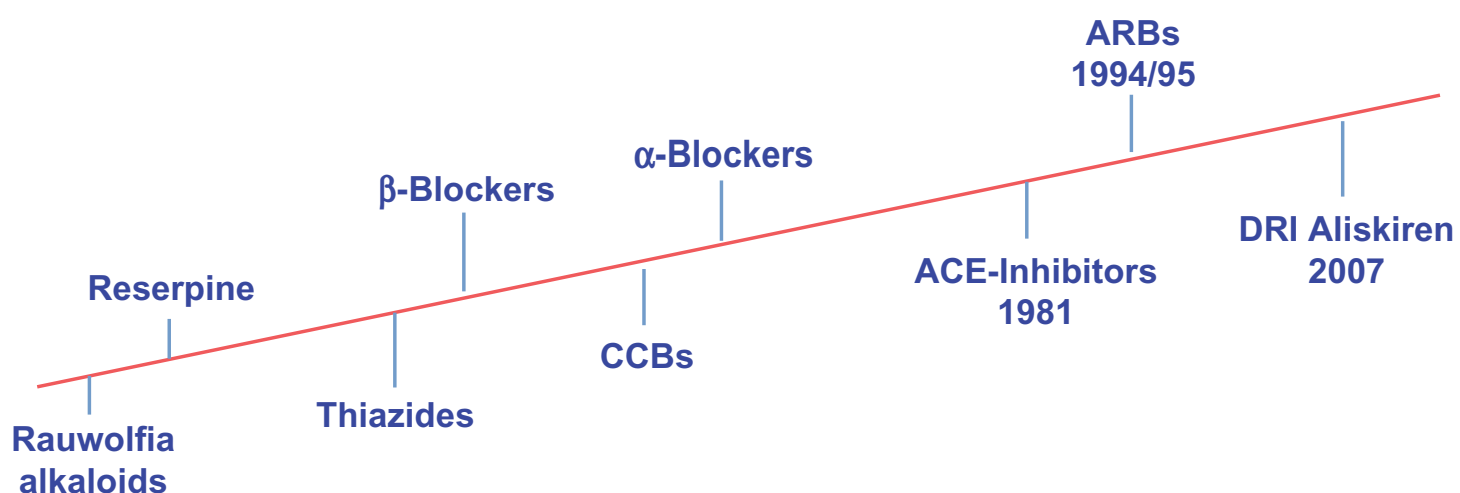

Figure I Evolution of antihypertensive drugs.

Abbreviations: ACE, angiotension-converting enzyme; $A R B s$, angiotensin receptor blockers; $C C B s$, calcium channel blockers; DRI, direct renin inhibitor.

uncontrolled blood pressure despite the enormous advances in antihypertensive-drug therapy represents a paradox. ${ }^{5}$ The term "paradox" refers to something unexpected and unexplained and is probably overused in the context of medical issues. Thus, the so-called hypertension paradox may, at least in part, be explained by epidemiological facts (global increase in overweight and obesity) and shortcomings and failures in coping with hypertension by doctors and patients.

Doctors may start treatment and nevertheless not reach target blood pressure values in their patients due to "therapeutic inertia", defined as a failure to expand therapy when treatment goals are unmet. Thus, in a recent Canadian study in 7253 treated hypertensive patients, antihypertensive therapy was increased in only $13.1 \%$ of visits with uncontrolled blood pressure. ${ }^{6}$ Therapeutic inertia may therefore be regarded as an additional factor contributing to insufficient blood pressure control in hypertensive subjects receiving regular care. In that study, predictors of therapeutic inertia were treated patients with stage 1 as compared to stage 2 hypertension and patients on fewer antihypertensive medications. It may therefore be speculated that the total number of medications may be important for the physician's response to a patient not at goal blood pressure with a higher likelihood of therapeutic inertia if that number is low.

The most important impediment to reaching goal blood pressure in treated hypertensive patients, however, may involve patients themselves. Not adhering to a prescribed therapy, usually termed non-compliance, remains a great challenge to any - especially chronic - drug treatment. In this context, it should be recognized that non-adherence with drug therapy is of multifactorial origin. Among the many reasons and supporting circumstances, the complexity of drug therapy itself has been identified as one factor associated with non-adherence. This brief review focuses on this issue and describes the possible role of so-called fixed-dose or single-pill combinations in improving this aspect of antihypertensive therapy.

\section{Hypertension - the need for combination therapy}

Various clinical trials have demonstrated that the majority of patients need treatment with multiple antihypertensive agents to get to and stay at blood pressure goal. The number of antihypertensive agents required for blood pressure control averages 2 to 4, with co-morbid conditions such as kidney disease or diabetes mellitus imposing even greater drug requirement. ${ }^{7,8}$ For example, in the Hypertension Optimal Treatment (HOT) study, an average of 3.3 drugs were required in patients aimed at a diastolic blood pressure goal of $<80 \mathrm{mmHg},{ }^{8}$ and in the Anglo-Scandinavian Cardiac Outcomes Trial-Blood Pressure Lowering Arm (ASCOT-BPLA), most patients (78\%) were taking at least 2 antihypertensive agents by the end of the trial. ${ }^{9}$ In the Avoiding Cardiovascular Events Through Combination Therapy in Patients Living with Systolic Hypertension (ACCOMPLISH) trial, patients were receiving initial treatment with single-pill combinations of 2 antihypertensive agents. ${ }^{10}$ In this study, $32.3 \%$ of the patients received additional antihypertensive agents on top of the highest dose of the dual combination after 1 year. This would indicate that about one-third of the patients in the ACCOMPLISH trial needed 3 and more antihypertensive agents to get and maintain their blood pressure at goal. Acknowledging the wide range of distribution for the number of antihypertensive agents used in the different intervention trials, it nevertheless appears reasonable to propose a rule of thumb whereby one-third of unselected hypertensive patients will have their blood pressure controlled 
with a single agent, one-third need 2 drugs and one-third will need 3 and more antihypertensive substances. In this context, it is of interest to note that hypertension is usually defined resistant or refractory to treatment when therapy with lifestyle measures and drug therapy of at least three agents including a diuretic in adequate doses has failed to lower systolic and diastolic blood pressure to goal., ${ }^{2,11,12}$ According to this definition prevalence of resistant hypertension is high: for instance in the ALLHAT cohort about $8 \%$ of the patients were prescribed 4 or more drugs at year 4 (chlorthalidone $5.5 \%$, amlodipine $8.5 \%$ and lisinopril $12.7 \%) .{ }^{13}$ The high rate of patients receiving $>3$ drugs in the lisinopril group of the ALLHAT trial may be due to the unfavorable add-on procedure for an angiotensin converting enzyme (ACE) inhibitor which consisted of atenolol, clonidine or reserpine as step 2 drugs. However, it may be fair to assume the percentage of resistant patient in the range of $5 \%$ to $10 \%$.

\section{Two-drug combinations}

Significant discrepancies exist on the question of which combinations of antihypertensive drugs should be employed. While the US-American JNC-7 recommendation from 2003 asks for a diuretic to be "usually" contained in a 2-drug combination strategy, the European guideline recommends various combinations both with and without a diuretic. ${ }^{2,12}$ More specifically, the recently revised European (ESC/ESH) guidelines recommend the following options for 2-drug combinations: diuretic plus either calcium channel blocker (CCB) or renin-angiotensin system (RAS) blocker (ACE inhibitor or angiotensin receptor blocker) or CCB plus RAS blocker. ${ }^{14}$ An additional discrepancy between US-American and European guidelines concerns the use of $\beta$-blocker-diuretic combinations which are supported by JNC $-7^{2}$ but commented on very critically in the European guidelines from $2007^{12}$ and their reappraisal in 2009. ${ }^{14}$ It appears, however, that much of this discrepancy stems from the fact that JNC-7 was published in 2003 when important studies influencing the European view such as $\mathrm{ASCOT}^{9}$ and ACCOMPLISH ${ }^{10}$ were not yet published. In the context of the current analysis, however, it is important to note that at present all recommended 2-drug combinations, according to both the US or European guidelines, are available as single-drug combinations.

\section{Three-drug combinations}

In the absence of large studies investigating triple therapies, guidelines were so far unable to make evidence-based recommendations. Thus, in JNC-7 it is stated that one should "optimize dosages or add additional drugs" in the case of uncontrolled hypertension with dual combination therapy. ${ }^{2}$ The European guidelines of 2007 make no recommendation at all. ${ }^{12}$ In contrast, the reappraisal of the European guidelines from 2009 makes the following statement: "When three drugs are required, the most rational combination appears to be a blocker of the renin-angiotensin system, a calcium antagonist, and a diuretic at effective doses". ${ }^{14}$ This recommendation is supported by a recent trial in 2271 hypertensive patients (blood pressure $\geq 145 / 100 \mathrm{mmHg}$ ) who were randomized to either a triple combination therapy of a RAS blocker (valsartan), a CCB (amlodipine) and a diuretic (hydrochlorothiazide [HCT]) or to the respective 2-drug combinations (RAS blocker + HCT, RAS blocker + CCB, $\mathrm{CCB}+\mathrm{HCT}) .{ }^{15}$ In that short-term study, triple therapy was significantly superior to the respective dual therapies in reducing mean sitting systolic and diastolic blood pressure from baseline to end point. Significantly more patients on triple therapy achieved blood pressure control compared with each dual therapy. ${ }^{15}$ It is of interest that this particular triple combination has recently been approved as a single-pill combination at various doses for antihypertensive treatment both in the US and in Europe.

\section{Combination therapy as separate pills vs single-pill combinations}

Adherence with prescribed medical therapy is generally poor. ${ }^{16}$ Over the past decades, several underlying factors for this problem have been identified including forgetfulness and conscious decisions by patients. ${ }^{17,18}$ One among many causal factors involved in this context is the complexity of therapy, ie, the number of prescribed medications and dosing time-points. ${ }^{19,20}$ As an example, in a retrospective study of adherence with antihypertensive and lipid-lowering therapy in a US managed care plan, fewer other medications were associated with a higher likelihood of adherence (Figure 2). ${ }^{19}$ In this context, it is of interest that an increasing number of especially elderly patients with multiple morbidities do require complex therapies, often resulting in polypharmacy. ${ }^{21-23}$ On the other hand, physicians may be able to significantly improve adherence by reducing the pill burden of their patients ${ }^{19}$ which can be achieved by the use of fixeddose or single-pill combinations.

Numerous studies have shown that whenever 2 agents are needed, eg, for lowering of blood pressure in hypertensive patients or for metabolic control in diabetes patients, adherence is better when these agents are prescribed as single-pill combinations than as separate pills. ${ }^{24-26}$ As a 


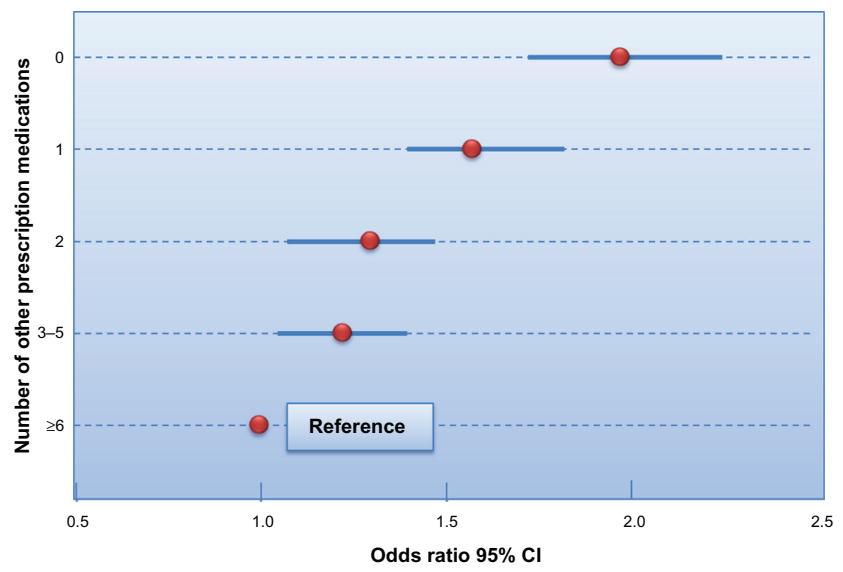

Figure 2 Analysis of predictors of adherence with antihypertensive and lipid-lowering medications. Shown is the odds ratio for adherence as a function of the number of other prescription medications. It is obvious that the total number of drugs is an important determinant of medication adherence. Drawn from data of Chapman et al. ${ }^{19}$

consequence, many hypertension guidelines therefore recommend multiple therapies to be provided as single pill combinations. ${ }^{2,12,14}$

Single-pill combinations have been criticized because of lesser flexibility in dosing associated with their use. It should be noted, however, that many single-pill combinations available offer different doses of, for example, RAS blocker, CCB or HCT. Thus, the term single-pill combination may indeed be more appropriate than fixed-dose combination. On the other hand, for patients with orthostatic problems or other co-morbidities such as congestive heart failure, even more careful dosing may be appropriate. In such patients, single-pill combinations should be used only after therapeutic conditions have been stabilized.

In summary, therapeutic inertia on the part of the treating physicians and non-adherence on the part of the patients are the two main factors responsible for the low percentage of treated hypertensive patients who reach goal blood pressure. The consequent use of single-pill combinations in accordance with national guidelines will, at least in part, improve medication adherence by the patients. It seems reasonable, but remains to be shown in clinical studies, that the use of fixed-dose combinations will also improve therapeutic inertia, since expanding therapy up to triple combinations with recommended treatment strategies can be prescribed without increasing the number of medications.

\section{Disclosures}

The author reports no conflicts of interest.

\section{References}

1. Kearney PM, Whelton M, Reynolds K, Muntner P, Whelton PK, He J. Global burden of hypertension: analysis of worldwide data. Lancet. 2005;365:217-223.

2. Chobanian AV, Bakris GL, Black HR, et al. and the National High Blood Pressure Education Program Coordinating Committee. Seventh Report of the Joint National Committee on Prevention, Detection, Evaluation, and Treatment of High Blood Pressure. JAMA. 2003;289:2560-2572.

3. Cutler JA, Sorlie PD, Wolz M, Thom T, Fields LE, Roccella EJ. Trends in hypertension prevalence, awareness, treatment, and control rates in United States adults between 1988-1994 and 1999-2004. Hypertension. 2008;52:818-827.

4. Wolf-Maier K, Cooper RS, Kramer H, et al. Hypertension treatment and control in five European countries, Canada, and the United States. Hypertension. 204;43:10-17.

5. Chobanian AV. The hypertension paradox - more uncontrolled disease despite improved therapy. $N$ Engl J Med. 2009;361:878-887.

6. Okonofua EC, Simpson KN, Jesri A, Rehman SU, Durkalski VL, Egan BM. Therapeutic inertia Is an impediment to achieving the healthy people 2010 blood pressure control goals. Hypertension. 2006;47:345-351.

7. Sica DA. Rationale for fixed-dose combinations in the treatment of hypertension. The cycle repeats. Drugs. 2002;62:443-462.

8. Bakris GL. The importance of blood pressure control in the patient with diabetes. Am J Med. 2004;116:30S-38S.

9. Dahlöf B, Sever PS, Poulter NR, et al. ASCOT Investigators. Prevention of cardiovascular events with an antihypertensive regimen of amlodipine adding perindopril as required versus atenolol adding bendroflumethiazide as required, in the Anglo-Scandinavian Cardiac Outcomes Trial-Blood Pressure Lowering Arm (ASCOT-BPLA): a multicentre randomised controlled trial. Lancet. 2005;366:895-906.

10. Jamerson K, Weber MA, Bakris GL, et al. for the ACCOMPLISH trial investigators. Benazepril plus amlodipine or hydrochlorothiazide for hypertension in high-risk patients. $N$ Engl $J$ Med. 2008;359: 2417-2428.

11. Setaro JF, Black HR. Refractory hypertension. $N$ Engl J Med. 1992;327:543-547.

12. The Task Force for the Management of Arterial Hypertension of the European Society of Hypertension (ESH) and of the European Society of Cardiology (ESC). 2007 Guidelines for the Management of Arterial Hypertension. J Hypertens. 2007;25:1105-1187.

13. The ALLHAT Officers and Coordinators for the ALLHAT Collaborative Research Group. Major outcomes in high-risk hypertensive patients randomized to angiotensin-converting enzyme inhibitor or calcium channel blocker vs diuretic: The Antihypertensive and Lipid-Lowering treatment to prevent Heart Attack Trial (ALLHAT). JAMA. 2002;288:2981-2997.

14. Mancia G, Laurent S, Agabiti-Rosei E, et al. Reappraisal of European guidelines on hypertension management: a European Society of Hypertension Task Force document. J Hypertens. 2009;27:2121-2158.

15. Calhoun DA, Lacourcière Y, Chiang YT, Glazer RD. Triple antihypertensive therapy with amlodipine, valsartan, and hydrochlorothiazide: a randomized clinical trial. Hypertension. 2009;54:32-39.

16. Berg JS, Dischler J, Wagner DJ, Raia JJ, Palmer-Shevlin N. Medication compliance: a healthcare problem. Ann Pharmacother. 1993;27(suppl):1-24.

17. Metry J-M ed. Drug Regimen Compliance: Issues in Clinical Trials and Patient Management. Métry J-M ed. John Wiley and Son Ltd.; 1999.

18. Düsing R, Weisser B, Mengden T, Vetter H. Changes in antihypertensive therapy - the role of adverse effects and compliance. Blood Press. 1998;7:313-315.

19. Chapman RH, Benner JS, Petrilla AA, et al. Predictors of adherence with antihypertensive and lipid-lowering therapy. Arch Int Med. 2005;165:1147-1152.

20. Osterberg L, Blaschke T. Adherence to medication. $N$ Engl J Med. 2005;353:487-497. 
21. Kaufman DW, Kelly JP, Rosenberg L, Anderson TE, Mitchell AA. Recent patterns of medication use in the ambulatory adult population of the United States. The Sloane Survey. JAMA. 2002;287:337-344.

22. Bjerrum L, Sogaard J, Hallas J, Kragstrup J. Polypharmacy: correlation with sex, age and drug regimen. A prescription database study. Eur $J$ Clin. Pharmacol. 1998;54:197-202.

23. Hajjar ER, Cafiero AC, Hanlon JT. Polypharmacy in elderly patients. Am J Geriatr Pharmacother. 2007;5:345-351.

24. Dezii CM. A retrospective study of persistence with single-pill combination therapy vs concurrent two-pill therapy in patients with hypertension. Manag Care. 2009;(suppl):2-6.
25. Brixner DI, Jackson KC 2nd, Sheng X, Nelson RE, Keskinaslan A. Assessment of adherence, persistence, and costs among valsartan and hydrochlorothiazide retrospective cohorts in free-and fixed-dose combinations. Curr Med Res Opin. 2008;24:597-607.

26. Blonde L, Wogen J, Kreilick C, Seymour AA. Greater reductions in $\mathrm{A} 1 \mathrm{C}$ in type 2 diabetic patients new to therapy with glyburide/ metformin tablets as compared to glyburide co-administered with metformin. Diabetes Obes Metab. 2003;5:424-431.

\section{Publish your work in this journal}

Vascular Health and Risk Management is an international, peerreviewed journal of therapeutics and risk management, focusing on concise rapid reporting of clinical studies on the processes involved in the maintenance of vascular health; the monitoring, prevention and treatment of vascular disease and its sequelae; and the involvement of metabolic disorders, particularly diabetes. This journal is indexed on PubMed Central and MedLine. The manuscript management system is completely online and includes a very quick and fair peer-review system, which is all easy to use. Visit http://www.dovepress.com/ testimonials.php to read real quotes from published authors.

Submit your manuscript here: http://www.dovepress.com/vascular-health-and-risk-management-journal 